\title{
The effect of smoking on exacerbation risk in eosinophilic patients with COPD
}

\author{
To the Editor:
}

We read with interest the findings of KERKHOF et al. [1], demonstrating an increased exacerbation risk in eosinophilic patients (eosinophil counts $\geqslant 0.45 \times 10^{9} \cdot \mathrm{L}^{-1}$ ) with chronic obstructive pulmonary disease (COPD). When compared to a normal reference group (eosinophil counts of between 0.05 and $0.45 \times 10^{9} \cdot \mathrm{L}^{-1}$ ), the rate ratios (RR) for exacerbations in the following year were lower in current smokers $(R R=0.86)$ than in ex-smokers $(R R=1.32)$. This finding is counter-intuitive and contrasts with data from large studies that demonstrate exacerbation reductions in COPD patients who cease smoking [2, 3]. A suppressive effect of active tobacco smoke on eosinophils is proposed as an explanatory mechanism by the authors; however, we feel the impact of potential confounders on this study finding should first be excluded prior to accepting this rationale.

The ECLIPSE study demonstrated that the strongest predictor of future exacerbations is prior exacerbations [4]. Despite this, data regarding the number of exacerbations in the preceding year were not reported or controlled for as a potential confounder in the predictive modelling. Why might this be important? Because the higher exacerbation rate in the ex-smoker subgroup could reflect a higher number of prior exacerbations (or a greater proportion of "frequent exacerbator" phenotypes). Why might this be relevant to ex-smokers? Because severe, potentially life-threatening COPD exacerbations can be potent stimuli for smoking cessation, thus increasing the likelihood of ex-smokers having a significant exacerbation history. It is therefore plausible that KeRKHOF et al. [1] have reported upon eosinophilic ex-smokers with a history of prior exacerbations. If this is true, both prior exacerbations and high eosinophil counts may have predisposed subjects to the observed increase in exacerbation risk, with smoking status representing a simple proxy for prior exacerbations.

A number of other factors are potentially problematic. The data originated from a large UK-based national databank derived primarily from primary care. While findings from such "real life" data might differ from those derived from "typical" patients recruited into clinical trials (as acknowledged by the authors), one must also consider the inherent potential for error associated with retrofitting the authors' specific research question to such a data source. There is potential for unintended recruitment bias related to the availability and completeness of outcome data. There is also potential for eosinophil group misclassification due to the presence of unknown co-existing acute inflammatory illness or oral corticosteroid use (both likely to suppress eosinophil counts below subjects' usual levels). Finally, there is potential for inaccuracy in exacerbation detection due to inconsistent definitions (e.g. antibiotic/acute corticosteroid prescription versus hospital/emergency department presentations). This is particularly important as the criteria for defining exacerbations are known to vary greatly in terms of their sensitivity to detect exacerbations of differing severity [5]. Sensitivity analyses related to exacerbation definition would be helpful to address this concern.

Tailored therapies can improve clinical outcomes for COPD patients who have distinct clinical phenotypes, and blood eosinophils have emerged as a simple, attractive potential stratification metric for this purpose. The findings of KеRкHOF et al. [1] offer interesting insights into the possible future priority areas for clinical research in this field. However, careful consideration and prospective evaluation are first required in order to confirm the interactions between eosinophils, COPD and other clinically impactful variables.

@ERSpublications

Higher exacerbation risk in COPD ex-smokers could reflect higher prior exacerbation history http://ow.ly/TbwP30fJNGj

Cite this article as: Osadnik CR, MacDonald MI, Bardin PG. The effect of smoking on exacerbation risk in eosinophilic patients with COPD. Eur Respir J 2017; 50: 1701820 [https://doi.org/10.1183/ 13993003.01820-2017]. 
Christian R. Osadnik $\oplus^{1,2}$, Martin I. MacDonald ${ }^{1,2}$ and Philip G. Bardin ${ }^{1,2}$

${ }^{1}$ School of Primary and Allied Health Care, Monash University, Melbourne, Australia. ${ }^{2}$ Monash Lung and Sleep, Monash Health, Melbourne, Australia.

Correspondence: C.R. Osadnik, School of Primary and Allied Health Care, Monash University, Peninsula Campus, McMahons Road, Melbourne (Frankston), Victoria 3199, Australia. E-mail: christian.osadnik@monash.edu

Received: Sept 052017 | Accepted: Sept 062017

Conflict of interest: Disclosures can be found alongside this article at erj.ersjournals.com

\section{References}

1 Kerkhof M, Sonnappa S, Postma DS, et al. Blood eosinophil count and exacerbation risk in patients with COPD. Eur Respir J 2017; 50: 1700761.

2 Au DH, Bryson CL, Chien JW, et al. The effects of smoking cessation on the risk of chronic obstructive pulmonary disease exacerbations. J Gen Intern Med 2009; 24: 457-463.

3 Godtfredsen NS, Vestbo J, Osler M, et al. Risk of hospital admission for COPD following smoking cessation and reduction: a Danish population study. Thorax 2002; 57: 967-972.

4 Hurst JR, Vestbo J, Anzueto A, et al. Susceptibility to exacerbation in chronic obstructive pulmonary disease. N Engl J Med 2010; 363: 1128-1138.

5 Pauwels R, Calverley P, Buist AS, et al. COPD exacerbations: the importance of a standard definition. Respir Med 2004; 98: 99-107.

Copyright @ERS 2017

From the authors:

We thank C.R. Osadnik and co-workers for raising these comments and would like to explain the rationale behind our chosen strategy of analyses.

Our previous work on risk factors of frequent chronic obstructive pulmonary disease (COPD) exacerbations confirms the authors' statement that a recent history of exacerbations is the strongest risk predictor of future exacerbations [1]. This strong association is probably caused by factors, mostly unknown, that are consistently present and influencing the degree of airway inflammation [2]. One of these factors may be increased migration of eosinophils from the circulation to the airways [3]. Little is known about the long-term course of eosinophilic airway inflammation in COPD, but some patients may have persistent eosinophilic inflammation, whereas in others eosinophilic inflammation may be intermittently present. This theory is supported by our unpublished work analysing the stability of blood eosinophil counts over time in patients diagnosed with COPD from the Optimum Patient Care Research Database (OPCRD; http://opcrd.co.uk), in which we find a within-patient correlation coefficient of 0.56 .

We agree with the authors that it is important to correct for baseline differences in exacerbation rates between study arms when studying effectiveness of specific interventions to achieve comparison groups that are similar in exacerbation risk at the start. By doing so, a potential change in exacerbation rate from baseline to outcome year caused by the intervention will be the focus of the outcome analyses.

However, the aim of our observational study, like similar studies [4], was to evaluate the association between blood eosinophil counts and exacerbation risk of patients with COPD. Patients with persistent eosinophilic inflammation are likely to have increased rates of exacerbations over both the baseline and the outcome year due to the same underlying mechanism. These persistent effects would be dampened by additional adjustment for the baseline exacerbation rate, which would change the focus towards a change in exacerbation rate from baseline to outcome period. In our opinion, the baseline exacerbation rate does not fulfil the definition of a real confounder, i.e. an extraneous factor that is associated with the exposure under study (eosinophils) and also predictive of disease occurrence (exacerbations) [5], but instead is an intermediate factor on the pathway from persistent recruitment of eosinophils to exacerbations. The

@ERSpublications

Adjusting for prior history of outcome variable may lead to overadjustment bias in observational studies http://ow.ly/627230gCBFd

Cite this article as: Kerkhof M, Hillyer EV, Price DB. The effect of smoking on exacerbation risk in eosinophilic patients with COPD. Eur Respir J 2017; 50: 1702086 [https://doi.org/10.1183/13993003.020862017]. 
suggested adjustment could thus be defined as an overadjustment in the context of intermediate variables, which would bias the results towards the null [6].

Indeed, the rate ratio of the association in ex-smokers is reduced from 1.32 to 1.18 (95\% CI 1.04-1.34) when the analyses were additionally adjusted for the number of baseline exacerbations, which nonetheless is still significant, suggesting that some of the effect is caused by varying eosinophil levels.

The authors also suggest that a so-called "healthy smoker effect" may have biased the association between blood eosinophil count and exacerbation rate, namely, the tendency of people who tolerate cigarettes to continue smoking, whereas those who experience serious health problems tend to quit [7]. We cannot fully rule this out, but there is no reason to assume that this tendency would be very different between patients with and without high blood eosinophil counts, unless the health problems are related to these counts. Moreover, $43 \%$ of all patients were still smoking, as were $39 \%$ of patients with frequent exacerbations in the baseline year, illustrating that smoking cessation can be very difficult for patients with COPD.

We acknowledge C.R. Osadnik and co-workers' concern regarding the potential for selection bias; however, a full blood count is a common blood test to check a person's general health or to screen for conditions such as anaemia, which will limit the amount of eosinophil group misclassification due to the presence of unknown acute co-existing inflammatory illness. Additional adjustment for comorbidities did not relevantly influence the results.

Finally, we would like to emphasise that further research is needed to shed more light on our observations.

Marjan Kerkhof, Elizabeth V. Hillyer $(\mathbb{C}$ and David B. Price $\odot$, on behalf of all authors

Observational and Pragmatic Research Institute (OPRI), Singapore.

Correspondence: David Price, Observational and Pragmatic Research Institute, 60 Paya Lebar Road, Paya Lebar Square, \#05-33/34, 409051, Singapore. E-mail: dprice@opri.sg

Received: Oct 102017 | Accepted: Oct 102017

Support statement: Funded by the Respiratory Effectiveness Group. Funding information for this article has been deposited with the Crossref Funder Registry.

Conflict of interest: Disclosures can be found alongside this article at erj.ersjournals.com

\section{References}

1 Kerkhof M, Freeman D, Jones R, et al. Predicting frequent COPD exacerbations using primary care data. Int J Chron Obstruct Pulmon Dis 2015; 10: 2439-2450.

2 Brightling CE. Chronic obstructive pulmonary disease phenotypes, biomarkers, and prognostic indicators. Allergy Asthma Proc 2016; 37: 432-438.

3 Bafadhel M, McKenna S, Terry S, et al. Acute exacerbations of chronic obstructive pulmonary disease: identification of biologic clusters and their biomarkers. Am J Respir Crit Care Med 2011; 184: 662-671.

4 Vedel-Krogh S, Nielsen SF, Lange P, et al. Blood eosinophils and exacerbations in chronic obstructive pulmonary disease. The Copenhagen General Population Study. Am J Respir Crit Care Med 2016; 193: 965-974.

5 Rothman KJ, Greenland S, Lash TL. Modern Epidemiology. Philadelphia, Lippincott Williams \& Wilkins, 2008.

6 Schisterman EF, Cole SR, Platt RW. Overadjustment bias and unnecessary adjustment in epidemiologic studies. Epidemiology 2009; 20: 488-495.

7 Bednarek M, Gorecka D, Wielgomas J, et al. Smokers with airway obstruction are more likely to quit smoking. Thorax 2006; 61: 869-873. 